\title{
Inhibition of transforming growth factor- $\beta$ type I receptor signaling by RNA interference suppresses the proliferation, collagen synthesis, and inflammation factors in human embryonic lung fibroblasts
}

\author{
Shihui Lin ${ }^{\mathrm{a}, \dagger}$, Juan Fu ${ }^{\mathrm{b}, \mathrm{a}, \dagger}$, Chuanjiang Wang ${ }^{\mathrm{a}}$, Qiong Liu ${ }^{\mathrm{a}}$, Fang $\mathrm{Xu}^{\mathrm{a}, *}$, Yuanzheng Yang ${ }^{\mathrm{c}, *}$ \\ a Department of Emergency and Critical Care Medicine, The First Affiliated Hospital of Chongqing \\ Medical University, Chongqing 400016 China \\ b Department of Emergency, Foshan First Peopl's Hospital, Foshan 528000 China \\ c Department of Critical Care Medicine, The Affiliated Hospital of Hainan Medical College, Haikou \\ 570102 China
}

*Corresponding authors, e-mail: xufang828@126.com, hhyangyuanzheng@163.com

$\uparrow$ These authors contributed equally to this work.

Received 5 Dec 2019

Accepted $10 \mathrm{Jul} 2020$

\begin{abstract}
Transforming growth factor- $\beta 1$ (TGF- $\beta 1$ ) is an important mediator of pulmonary fibrosis. The purpose of this study was to determine whether small interference RNA (siRNA) directed to the transforming growth factor- $\beta$ type I receptor (T $\beta$ RI) could be used to suppress the action of TGF- $\beta 1$ in human embryonic lung fibroblasts (HELF). Here we constructed 4 specific recombinant lentivirus vectors, targeting the T $\beta$ RI gene to transfect the HELF. We observed their effects on T $\beta R I$ expression using real-time PCR and Western blot. The HELF were stimulated with TGF- $\beta 1$ after transfection with lentivirus vectors. The expression of p-Smad3 was measured using Western blot. The proliferation activity of the HELF was determined with an MTT assay, the cell cycle was analyzed using flow cytometry, the collagen expression was observed with Sirius Red staining, the expression of $\alpha$-smooth muscle actin ( $\alpha$-SMA) was measured using RT-PCR, and the supernatant tumor necrosis factor- $\alpha$ (TNF- $\alpha$ ), interleukin- 6 (IL-6), collagen I and collagen III levels were measured with ELISA testing. We found that T $\beta$ RI siRNA abrogated the receptor transcription and protein expression in growing HELF. The lentivirus-mediated siRNA targeting the T $\beta$ RI gene could inhibit the activation of HELF and the expression of p-Smad3 stimulated by TGF- $\beta 1$, and effectively suppressed its effects on cell proliferation, the cell cycle, collagen synthesis, $\alpha$-SMA, collagen I, collagen III, TNF- $\alpha$ and IL- 6 expression in HELF. T $\beta$ RI-specific siRNAs were efficacious in knocking down TGF- $\beta 1$ action in vitro. Application of siRNA in HELF to downregulate T $\beta$ RI expression may provide a novel therapy for preventing pulmonary inflammation and fibrosis.
\end{abstract}

KEYWORDS: Acute respiratory distress syndrome, pulmonary fibrosis, RNA interference, transforming growth factor$\beta 1$, transforming growth factor- $\beta$ type I receptor, human embryonic lung fibroblasts

\section{INTRODUCTION}

Acute respiratory distress syndrome (ARDS) is a clinical syndrome that is characterized by respiratory distress and refractory hypoxemia, with extremely high morbidity and mortality $[1,2]$. Mechanical ventilation is the main treatment for ARDS [3]. However, many mechanically ventilated patients with ARDS develop pulmonary fibrosis [4]. Pulmonary fibrosis is one of the common causes of death from ARDS. Transforming growth factor- $\beta 1$ (TGF- $\beta 1$ ) is a potent fibrogenic cytokine that plays a key role in pulmonary fibrosis. It is recognized as the most important regulatory factor in the study of organ and tissue fibrosis. Lung fibroblasts are one of the main cell types that express TGF- $\beta 1$, this growth factor can promote excessive proliferation and differentiation of lung fibroblasts and excessive deposition of extracellular matrix collagen in lung tissue [5]. Studies have shown that in sepsis-induced ARDS in baboons, persistent active collagen synthesis occurs within the fibroblastic foci and interalveolar septa. Fibroblasts express markers of TGF- $\beta$ and platelet-derived growth factor signaling, suggesting their potential role as media- 
tors of myofibroblast migration and proliferation, and collagen deposition [6]. These data suggest that TGF- $\beta$ may play a role in the development of acute lung injury, in addition to the regulation of fibroproliferation. Current research confirms that TGF- $\beta$ /Smad signaling plays an important role in injury and repairing $[7,8]$. In severe corona virus disease 2019 (COVID-19), severe carbon dioxide retention, hypercapnia, and pulmonary fibrosis in the later stage may involve excessive repair of lung. With HELF as the goal, exploring the role of TGF$\beta$ signaling will provide evidence for the balance between injury and repairing in severe ARDS.

TGF- $\beta$ signaling is initiated upon ligand binding to the TGF- $\beta$ receptor type II (T $\beta$ RII), which then recruits the receptor type I (T $\beta R I)$, also designated activin receptor-like kinase 5 (ALK5), into the receptor complex, producing subsequent phosphorylation of T $\beta R I / A L K 5$ and its downstream mediator proteins. T $\beta$ RI/ALK5 appears to be essential for the biological activity of the TGF- $\beta$ signaling pathway, and its inhibition or modification is considered to be a promising therapeutic strategy for the inhibition of pulmonary inflammation and fibrosis [9]. RNA interference (RNAi) can easily and efficiently inhibit the expression of a particular gene by triggering the disruption of mRNA sharing the same sequence as the double-stranded RNA of the specific gene and preventing target synthesis of proteins [10]. Since ligand binding by T $\beta R I$ appears to be an important limiting step in cellular activation, we used the RNAi strategy to direct this receptor, and further investigated the molecular mechanism of the TGF- $\beta$ signaling pathway in pulmonary inflammation and fibrosis. Since lung fibroblast cells are the major effector cells in progressive pulmonary fibrosis, we chose human embryonic lung fibroblasts to investigate the role of the TGF- $\beta$ /T $\beta$ RI signaling pathway in mediating cell proliferation, collagen synthesis, and inflammation.

\section{MATERIALS AND METHODS}

\section{Materials}

Materials: 293T Cell lines and human embryonic lung fibroblast cell lines MRC-5 were from Shanghai Institute of Biology, Chinese Academy of Sciences, China. Reagents were commercially purchased: $10 \%$ heat-inactivated fetal bovine serum (FBS), high-glucose Dulbecco's Modified Eagle Medium (DMEM), streptomycin and penicillin were from Gibco (Carlsbad, USA); Recombinant human TGF- $\beta 1$ from PeproTech (Rocky Hill, USA);
Table 1 Interfering sequence specified for T $\beta$ RI gene.

\begin{tabular}{|c|c|}
\hline Number & Sequence \\
\hline siRNA1 & $\begin{array}{l}\text { Oligo 1: 5'-CCGGCCATCTTCACATGGAGATTCTCAAGA } \\
\text { GAAATCTCCATGTGAAGATGGTTTTTTG-3' } \\
\text { Oligo2: } 5^{\prime} \text {-AATTCAAAAAACCATCTTCACATGGAGATT } \\
\text { TCTCTTGAGAATCTCCATGTGAAGATGG-3' }\end{array}$ \\
\hline siRNA2 & $\begin{array}{l}\text { Oligo } 1: 5^{\prime} \text {-CCGGGGAGATTGTTGGTACCCAATTCAAGA } \\
\text { GATTGGGTACCAACAATCTCCTTTTTTG-3' } \\
\text { Oligo2: } 5^{\prime} \text {-AATTCAAAAAAGGAGATTGTTGGTACCCAA } \\
\text { TCTCTTGAATTGGGTACCAACAATCTCC- } 3^{\prime}\end{array}$ \\
\hline siRNA3 & $\begin{array}{l}\text { Oligo } 1: 5^{\prime} \text {-CCGGTCAAGAGACCAAGGTACATTTCAAGA } \\
\text { GAATGTACCTTGGTCTCTTGATTTTTTG-3' } \\
\text { Oligo2: } 5^{\prime} \text {-AATTCAAAAAATCAAGAGACCAAGGTACAT } \\
\text { TCTCTTGAAATGTACCTTGGTCTCTTGA-3' }\end{array}$ \\
\hline siRNA4 & $\begin{array}{l}\text { Oligo 1: } 5^{\prime} \text {-CCGGTCCTAACACTACAGTAGAATTCAAGA } \\
\text { GATTCTACTGTAGTGTTAGGATTTTTTG-3' } \\
\text { Oligo2: } 5^{\prime} \text {-AATTCAAAAAATCCTAACACTACAGTAGAA } \\
\text { TCTCTTGAATTCTACTGTAGTGTTAGGA-3' }\end{array}$ \\
\hline
\end{tabular}

Rabbit-anti-TßRI, mouse-anti-phospho-Smad3 from Cell Signaling Technology (MA, USA); HRPconjugated goat anti-rabbit or anti-mouse from IgG Santa Cruz Biotechnology (TX, USA); SYBR Green PCR Master Mix reagents from Roche (Basel, Switzerland); MTT3-(4,5-dimethylthiazol2-yl)-2, 5-diphenyltetrazoliumbromide reagent from Sigma (MO, USA); bicinchoninic acid protein assay kit (BCA) from Beyotime Biotechnology (Jiangsu,China); Sirus Red from Hede Biotechnology (Beijing, China); ELISA reagents from R\&D Systems (CA, USA), and lentivirus packaging and expression plasmids from Sunbio Biomedical Technology (Shanghai, China).

\section{Construction of lentiviral vectors expressing T $\beta$ RI siRNA}

We designed and cloned a short hairpin RNA (shRNA) template into a previously used lentivirus vector. A third-generation selfinactivating lentivirus vector plasmid DNA of pMagic4.0/enhanced green fluorescent protein (EGFP) containing a cytomegalovirus (CMV)-driven EGFP reporter and an hU6 promoter upstream of the cloning sites (Age I and EcoR I) were used. The introduction of oligonucleotides encoding shRNAs between these restriction sites enabled the production of the shRNA in vivo. Four coding regions corresponding to targeting human T $\beta R I$ starting at positions 359, 360, 361, and 362 in the sequence (GenBank Accession: No. NM_004612) were selected as siRNA target sequences under the guide of siRNA designing software by Genscript. We constructed 4 shRNA-T $\beta R I$ lentivirus vectors: siRNA1, siRNA2, siRNA3, and siRNA4 (Table 1). To detect the interference effects of different 
targets, T $\beta$ RI mRNA and protein levels were determined using real-time PCR and Western blot analysis. Recombinant lentivirus vectors and negative control lentivirus vectors were produced by co-transfection with the lentivirus expression plasmid and packaging plasmids in 293T cells. Infectious lentiviruses were harvested at $72 \mathrm{~h}$ post-transfection, centrifuged, and filtered through $0.45-\mu \mathrm{m}$ cellulose acetate filters. The infectious titer was determined by a hole-by-dilution titer assay.

\section{Cell culture and T $\beta R I$ RNAi lentivirus particles transfected MRC-5 cells}

We cultured MRC- 5 cells on uncoated plastic tissue culture dishes in high-glucose DMEM and 10\% FBS, and added $100 \mu \mathrm{g} / \mathrm{ml}$ streptomycin and $100 \mathrm{U} / \mathrm{ml}$ penicillin. These cells were incubated at $37^{\circ} \mathrm{C}$ in $5 \% \mathrm{CO}_{2}$ and cultured on 6 parallel wells: nontransfected MRC-5 cells (normal control group, CON), negative control lentivirus vector transfected MRC-5 cells (negative control vector group, LV-NC), and lentivirus vector siRNA1-4 transfected MRC5 cells (siRNA1-4 group). When cell confluence reached $50-60 \%$, we added $6 \times 10^{6}$ transformation unit per well of the recombinant lentivirus to the plates, then cultured them for 3 days. An inverted fluorescence microscope was used to detect transfection efficiency.

\section{Real-time PCR detection of T $\beta$ RI mRNA expression}

Cells were collected at $48 \mathrm{~h}$ after transfection. Total RNA from the cells was extracted using RNAiso Plus reagent (TaKaRa, Dalian, China). The Prime Script ${ }^{\circledR}$ RT reagent kit (TaKaRa) was utilized to synthesize RNA to cDNA. SYBR Green Real-Time PCR Master Mix (Roche, USA) and RT-PCR amplification equipment using specific primers were employed to perform quantitative real-time polymerase chain reaction (RT-PCR) assays. T $\beta R I$, forward: $5^{\prime}$ TTGATATTGCTCCAAACCACAGAG-3', reverse: $5^{\prime}$ TACTAAGCCCATTGCATAGATGTC-3'; GAPDH, forward: 5'-GCACCGTCAAGGCTGAGAAC-3', reverse: TGGTGAAGACGCCAGTGGA- ${ }^{\prime}$. The threshold cycle $(\mathrm{Ct})$ of GAPDH was used as the control. Cycle parameters: $95^{\circ} \mathrm{C}$ initial denaturation for $10 \mathrm{~min}$, then denaturation for $10 \mathrm{~s}$, annealing at $59^{\circ} \mathrm{C}$ for $30 \mathrm{~s}, 38$ cycles in total, followed by $2 \mathrm{~min}$ at $72^{\circ} \mathrm{C}$.

\section{Western blot detection of $T \beta R I$ protein expression}

At $72 \mathrm{~h}$ post-transfection, cells were collected using RIPA lysis buffer to extract the protein from the MRC- 5 cells and the BCA protein assay kit to detect protein concentrations. Then, 10\% SDSPAGE was used to resolve equal amounts of proteins, and the proteins were then transferred to PVDF membranes for probing with the primary antibody and the peroxidase secondary antibody. Antibody and dilutions: rabbit anti-T $\beta$ RI antibody (1:1000), rabbit anti-GAPDH (1:2500), HRP-conjugated goat anti-rabbit IgG (1:2000). Enhanced chemiluminescence was used to detect the immunoreactive protein complexes.

\section{Western blot detection of p-Smad3 protein expression}

These cells were incubated at $37^{\circ} \mathrm{C}$ in $5 \% \mathrm{CO}_{2}$ and cultured on 6 parallel wells. The experiment was divided into four groups: normal control group (CON group), negative control lentivirus vector transfected MRC-5 cells group (LV-NC group), lentivirus vector siRNA transfected MRC- 5 cells group (siRNA group), and normal MRC-5 cells ready to give TGF$\beta 1$ stimulation group (TGF- $\beta 1$ group). At $48 \mathrm{~h}$ post-transfection in LV-NC group and siRNA group, the MRC-5 cells were seeded into culture plates. At $12 \mathrm{~h}$ later, these cells of LV-NC group, siRNA group and TGF- $\beta 1$ group were treated with TGF- $\beta 1$ $(5 \mathrm{ng} / \mathrm{ml})$. Cells were harvested after co-treatment for another $72 \mathrm{~h}$. Cells were collected using RIPA lysis buffer to extract the protein from the MRC-5 cells and the BCA protein assay kit to detect protein concentrations. Then, 10\% SDS-PAGE was used to resolve equal amounts of proteins, and the proteins were then transferred to PVDF membranes for probing with the primary antibody and the peroxidase secondary antibody. Antibody and dilutions: rabbit anti-p-Smad3 antibody (1:1500), rabbit antiSmad3 (1:1000), HRP-conjugated goat anti-rabbit IgG (1:2000). Enhanced chemiluminescence was used to detect the immunoreactive protein complexes. All expreiments were repeated three times using different samples.

\section{Cell proliferation assay}

At $48 \mathrm{~h}$ post-transfection, the MRC-5 cells were seeded into culture plates. At $12 \mathrm{~h}$ later, these cells were treated with TGF- $\beta 1(5 \mathrm{ng} / \mathrm{ml})$ or with a vehicle. Cells were harvested and cell proliferation was detected with a methylthiazo- 
lyldiphenyl-tetrazolium bromide (MTT) assay after co-treatment for another 24, 48, and $72 \mathrm{~h}$. Cells were stained with $20 \mu \mathrm{l}$ MTT $(5 \mathrm{mg} / \mathrm{ml})$ for $4 \mathrm{~h}$ at $37^{\circ} \mathrm{C}$. The culture supernatant was carefully aspirated and $150 \mathrm{ml}$ of DMSO was then added to each well. After $10 \mathrm{~min}$ of stirring, the absorbance values were evaluated at $570 \mathrm{~nm}$.

\section{Cell cycle analysis}

As with the above treatment, cells were collected and washed with PBS, after being co-treated for another $72 \mathrm{~h}$. Cells were centrifuged at $800 \mathrm{rpm}$, fixed with $70 \%$ ethanol and maintained overnight at $4{ }^{\circ} \mathrm{C}$, then permeabilized in a reagent consisting of $230 \mu \mathrm{g} / \mathrm{ml} \mathrm{RNase} \mathrm{A,} 50 \mu \mathrm{g} / \mathrm{ml}$ propidium iodide, and $0.5 \%$ Triton X-100 in PBS. Following flow cytometric analysis, all of the samples were maintained at $37^{\circ} \mathrm{C}$ for $30 \mathrm{~min}$.

\section{Sirius Red staining}

As with the above treatment, cells were harvested and rinsed with PBS, after being co-treated for another 24,48 , and $72 \mathrm{~h}$. The cells were fixed in ice-cold methanol, kept overnight at $-20^{\circ} \mathrm{C}$, then stained with $1 \%$ Sirius Red staining at room temperature for $1 \mathrm{~h}$. Sirius Red staining is specific for calcium deposition. Cells were rinsed thrice with $0.1 \%$ acetate for $15 \mathrm{~min}$. We then added $200 \mu \mathrm{l}$ of $0.1 \%$ sodium hydroxide solution to each well for $1 \mathrm{~h}$ while stirring gently. The absorbance of the extracted dye was measured using a Model 680 microplate reader at $540 \mathrm{~nm}$ (Thermo, Finland).

\section{RT-PCR detection of $\alpha$-SMA mRNA expression}

As with the above treatment, we separately extracted RNA from each group after the cells had been co-treated for another $72 \mathrm{~h}$. The total RNA from each sample was then extracted using the RNAiso Plus reagent (TaKaRa, China). The $\alpha$-SMA PCR primers were: forward: $5^{\prime}$ ATGTGTGAAGAAGAGGACAGCA-3'; reverse: $5^{\prime}$ TTGTAGAAAGAG TGGTGCCAGA- $3^{\prime}$. The GAPDH primers were the same as those used previously. The total RNA $(1 \mu \mathrm{g})$ extracted from the cultured cells was used for the RT reaction, and then $2 \mu l$ of cDNA was used for amplification at a final volume of $20 \mu \mathrm{l}$ according to the supplier's protocol (TaKaRa). Cycle parameters: $95^{\circ} \mathrm{C}$ initial denaturation for $30 \mathrm{~min}$, then denaturation for $30 \mathrm{~s}$, annealing at $61^{\circ} \mathrm{C}$ for $30 \mathrm{~s}$, extension at $72^{\circ} \mathrm{C}$ for $30 \mathrm{~s}, 38$ cycles in total, followed by 2 min at $72^{\circ} \mathrm{C}$. Each PCR product was subjected to electrophoresis on $2 \%$ agarose gel.

\section{Enzyme-linked immunosorbent assay}

As with the above treatment, cell supernatants were harvested after being co-treated for another $72 \mathrm{~h}$, then stored at $-80^{\circ} \mathrm{C}$ until they were analyzed. According to the ELISA reagents manufacturer's instructions, the concentrations of TNF- $\alpha$, IL- 6 , collagen I and collagen III were quantified.

\section{Statistical analysis}

All of the data were expressed as means \pm standard deviations. Statistical analyses were performed using one-way ANOVA with SPSS 18.0 software. Differences between groups of data were assessed with the SNK- $q$ test. $p<0.05$ was considered to be statistically significant.

\section{RESULTS}

\section{Transfection efficiency of the lentivirus vector}

The transfection efficiency of the recombinant lentivirus vectors that encoded shRNA against T $\beta R I$ as well as EGFP were analyzed using fluorescenceactivated cell sorting (FACS) for the EGFP expressed in the transfected MRC-5 cells (Fig. 1a). No differences were found among the virus titers of the viruses transfected with different types of shRNA. EGFP expression reached its peak when the MRC-5 cells were infected with the recombinant lentivirus vectors at the ratio of the multiplicity of infection (MOI) of 30 and cultured with $5 \mu \mathrm{g} / \mathrm{ml}$ polybrene. Transfection was efficient in that $>93 \%$ of the cells showed green fluorescent luciferase siRNA (EGFP) (data not shown). EGFP expression peaked when the MRC- 5 cells were infected with the recombinant lentivirus vectors at the MOI ratio.

\section{Effects of RNAi on gene expression of T $\beta R I$}

Real-time PCR showed that T $\beta R I$ expression was significantly lower in the siRNA1-4 groups than in the CON group, with T $\beta R I$ mRNA inhibition rates of $26.8 \%, 80.8 \%, 70.7 \%$, and $79.7 \%$, respectively ( $p<0.05$ in each group). siRNA2 was found to have the highest interfering efficiency (Fig. 1b).

\section{Effects of RNAi on protein expression of T $\beta R I$}

Western blot analysis showed that $\mathrm{T} \beta \mathrm{RI}$ expression was significantly lower in the siRNA1-4 groups than in the CON group, with $\mathrm{T} \beta \mathrm{RI}$ protein inhibition rates of $48.9 \%, 61.6 \%, 50.0 \%$, and $60.3 \%$, respectively ( $p<0.05$ in each group). siRNA2 was found to significantly decrease T $\beta R I$ expression relative to the other siRNA groups (Fig. 1c). We selected the 
(a)
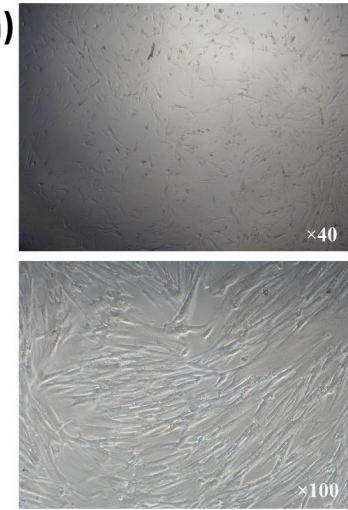

(c)

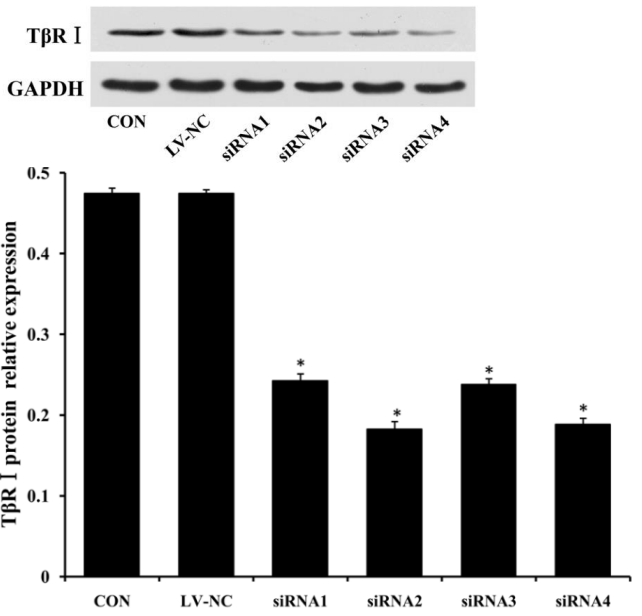

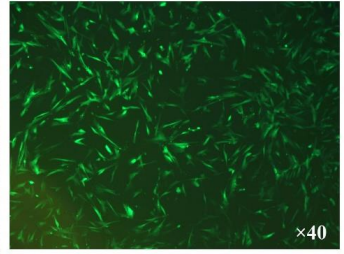

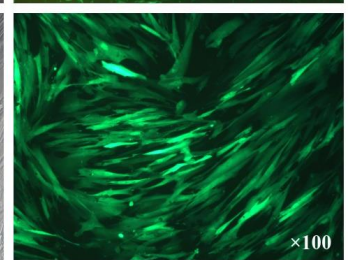

(d)
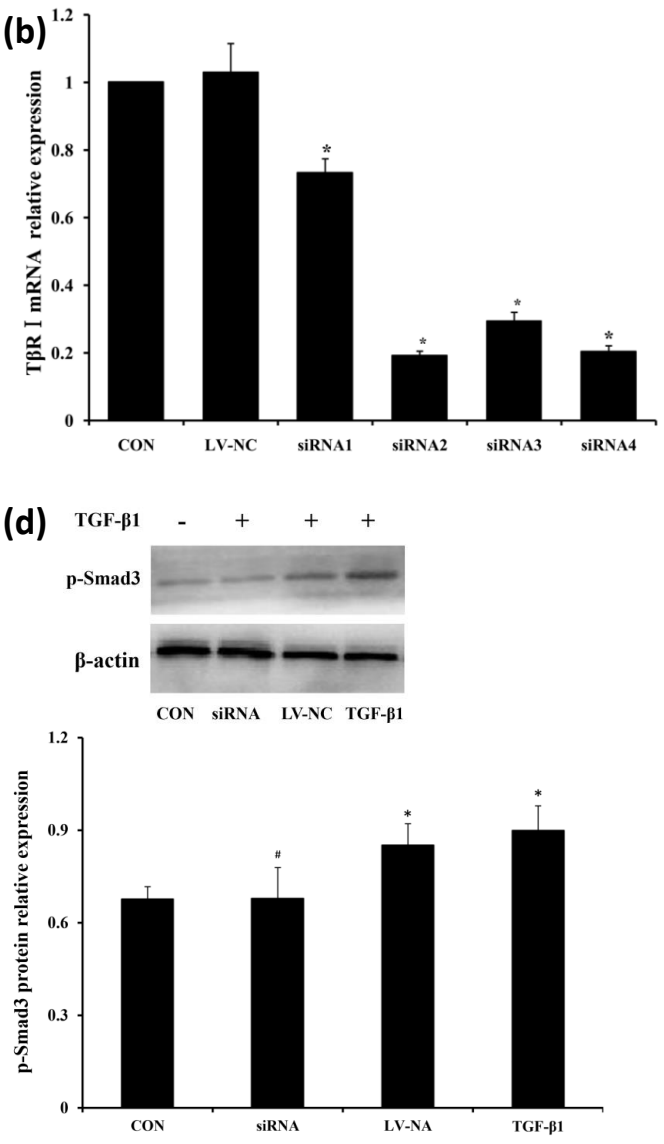

Fig. 1 Construction and screening of lentiviral RNA interference vectors targeting the T $\beta$ RI gene. (a) Green fluorescence was observed and used to detect transfection efficiency. (b) Quantitative real-time RT-PCR was performed to investigate transcription levels of T $\beta$ RI. (c) The protein expression levels of T $\beta R I$ in different groups were quantified relative to GAPDH expression by Western blot. (d) The protein expression levels of p-Smad3 in different groups were quantified relative to Smad3 expression by Western blot. * $p<0.05$ compared with the CON group. \# $p<0.05$ compared concurrently with the TGF- $\beta 1$ and the LV-NC groups.

siRNA2 lentivirus vector with the highest interfering efficiency for the following experiments.

\section{Effects of RNAi on protein expression of p-Smad3}

Western blot analysis showed that p-Smad3 expression was significantly higher in the TGF- $\beta 1$ group than in the CON group $(p<0.05)$. MRC-5 cells transfected by siRNA2 (siRNA group) were found to significantly decrease $\mathrm{p}$-Smad3 expression relative to the TGF- $\beta 1$ group $(p<0.05)$ (Fig. 1d).

\section{MTT assay}

The results of the MTT assay showed that, in comparison with the CON and TGF- $\beta 1$ groups, the MRC5 cells transfected by siRNA2 (siRNA group) exhibited a strong inhibition of MRC-5 cell proliferation at concurrent times $(p<0.05)$. However, the MRC5 cells did not show a difference among the CON, TGF- $\beta 1$, and negative control vector (LV-NC) groups at concurrent times ( $p>0.05)$ (Fig. 2a).

\section{Cell cycle assay}

When compared to the CON and TGF- $\beta 1$ groups, the results of the cell cycle assay performed on the siRNA group revealed obvious changes in the cell ratio. The MRC- 5 cells had a higher ratio for the $S$ phase and a lower ratio for the G0/G1 and G2/M phases $(p<0.05)$. However, the cell cycle assay did not show evident changes in the cellular relationship between the CON, TGF- $\beta 1$, and LV-NC group ( $p>$ 0.05) (Fig. 2b). 
(a)

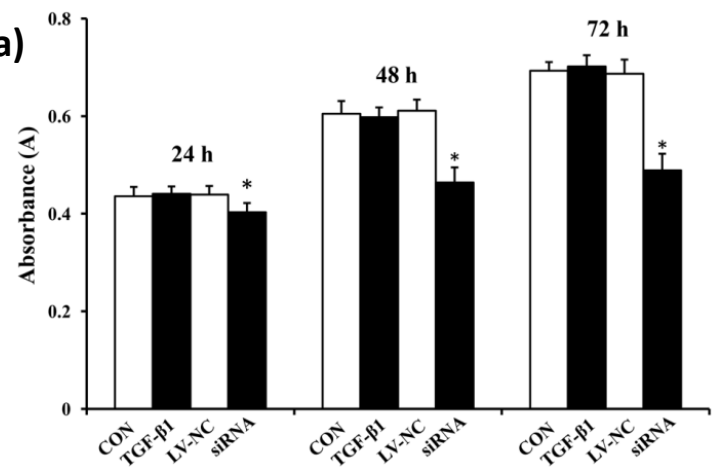

(b)
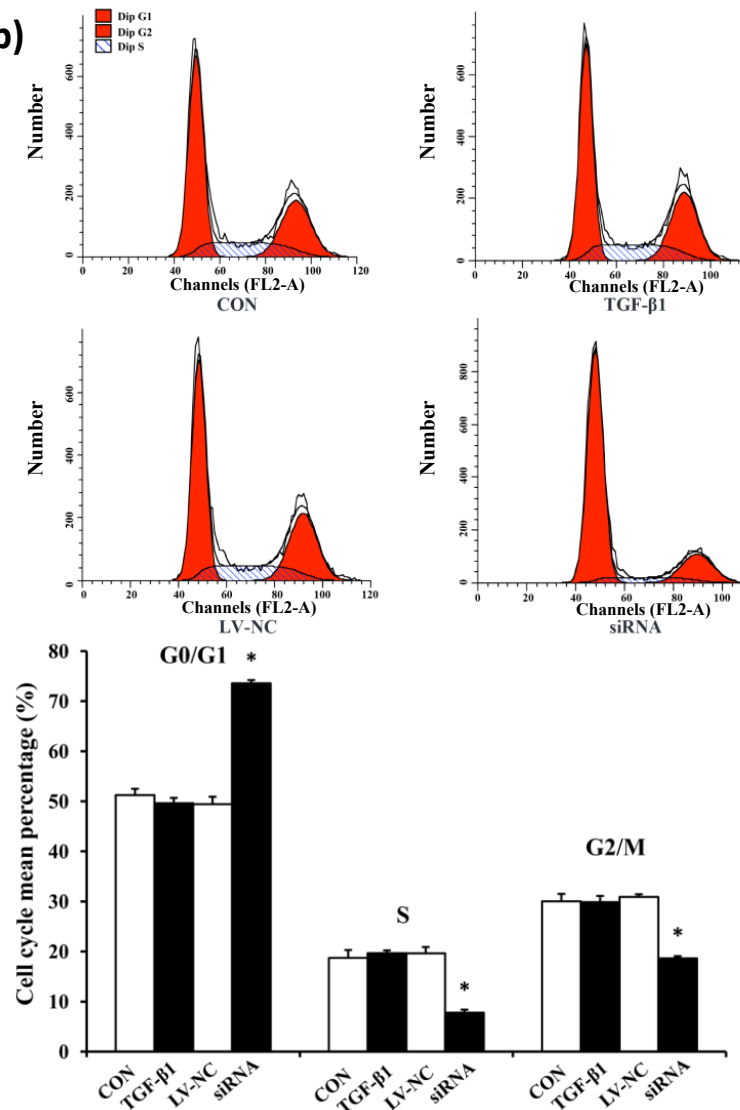

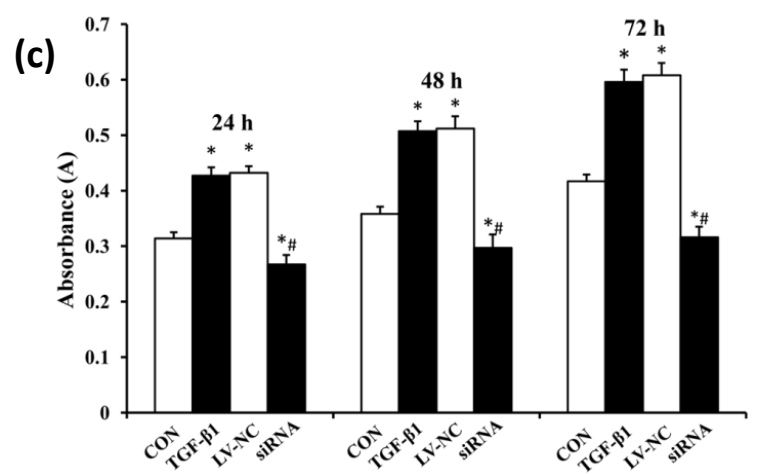

(d)
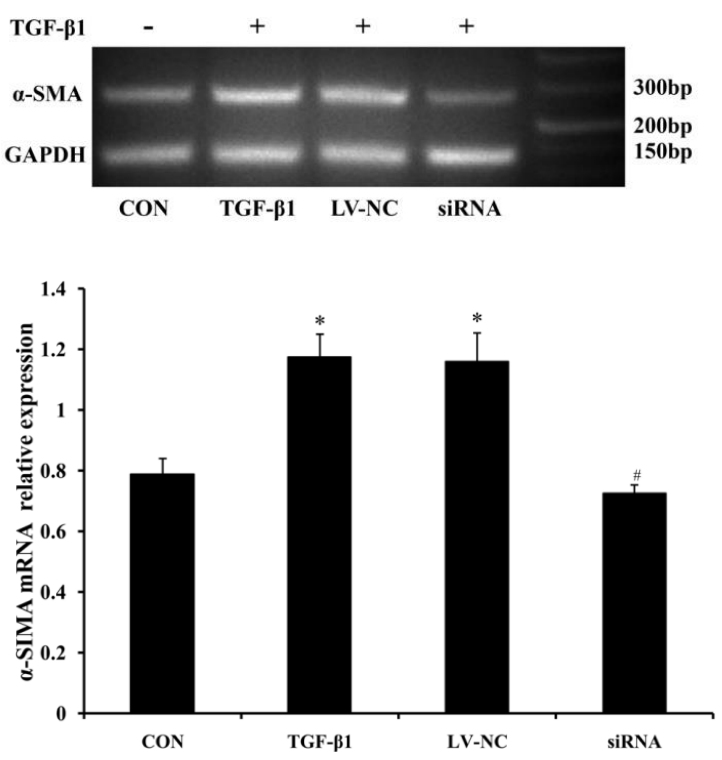

Fig. 2 Effect of TGF- $\beta 1$ on proliferation and collagen synthesis of HELF. Cells were treated with either a vehicle or with $5 \mathrm{ng} / \mathrm{ml}$ TGF- $\beta 1$, then co-treated for another 24,48 , and $72 \mathrm{~h}$. (a) Cells were collected and stained with MTT. $* p<0.05$ compared concurrently with the TGF- $\beta 1$, LV-NC, and CON groups. (b) Cell cycle assays were detected using flow cytometry. $* p<0.05$ compared with the CON, TGF- $\beta 1$, and LV-NC groups. (c) Collagen synthesis was detected using Sirius Red staining. * $p<0.05$ compared concurrently with the CON. \# $p<0.05$ compared concurrently with the TGF- $\beta 1$ and the LV-NC groups. (d) The expression of $\alpha$-SMA mRNA by RT-PCR. * $p<0.05$ compared concurrently with the CON group. \# $p<0.05$ compared concurrently with the TGF- $\beta 1$ and the LV-NC group. LV-NC, negative control vector group; CON, normal control group.

\section{Collagen expression}

The results of the Sirius Red staining showed that the level of collagen expression was significantly higher in the TGF- $\beta 1$ group than in the CON group $(p<0.05)$. MRC-5 cells transfected by siRNA2 (siRNA group) were found to significantly restrain collagen synthesis $(p<0.05)$ (Fig. 2c). 

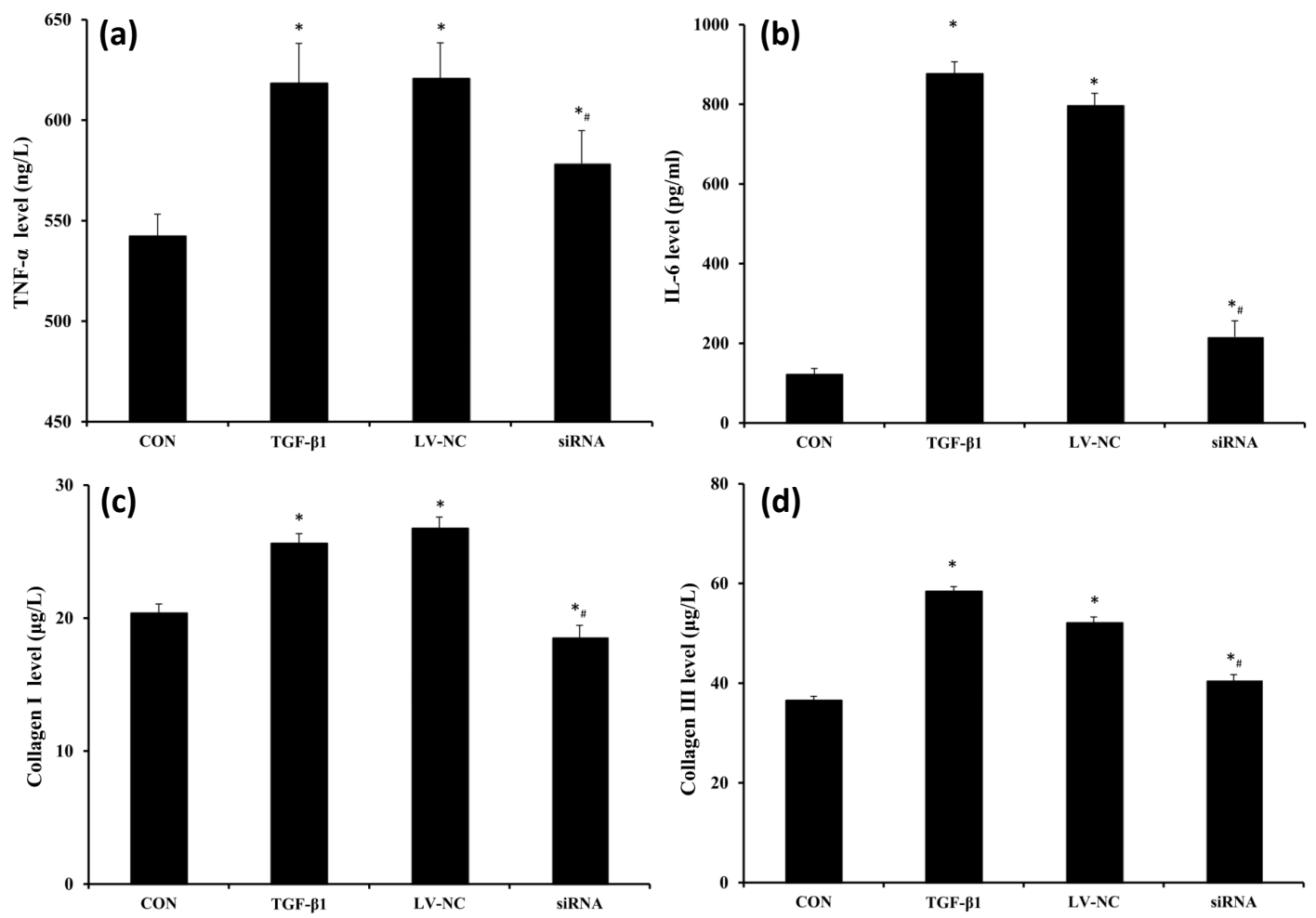

Fig. 3 The concentrations of TNF- $\alpha$, IL-6, collagen I and collagen III measured by ELISA. Each group $n=5$, * $p<0.05$ compared with the CON group. \# $p<0.05$ compared with the TGF- $\beta 1$ and LV-NC group, by the one-way ANOVA followed by LSD multiple comparisons test.

\section{Effects of RNAi on gene expression of $\alpha$-SMA}

RT-PCR showed that $\alpha$-SMA expression was significantly higher in the TGF- $\beta 1$ group than in the CON group $(p<0.05)$. MRC-5 cells transfected by siRNA2 were found to significantly decrease $\alpha$-SMA expression relative to the TGF- $\beta 1$ group $(p<0.05)$ (Fig. 2d).

\section{Effects of RNAi on TNF- $\alpha$, IL-6, collagen I and collagen III supernatant levels}

ELISA testing showed that the level of TNF- $\alpha$, IL- 6 , collagen I and collagen III in the supernatants were higher in the TGF- $\beta 1$ group than in the CON group $(p<0.05)$. When compared to the TGF- $\beta 1$ group, the level of TNF- $\alpha$, IL- 6 , collagen I and collagen III in the siRNA group was much lower $(p<0.05)$ (Fig. 3).

\section{DISCUSSION}

ARDS is a severe syndrome resulting from diffuse damage to pulmonary parenchyma. ARDS is also characterized pathologically by an early exudative, inflammatory phase, followed in many patients by a fibrotic phase. The inflammatory phase has been the focus of other studies [11]. Autopsy and histopathological examination of ARDS have revealed an early inflammatory phase followed by a fibroproliferative repair phase with matrix protein deposition, including collagen. Some patients progress to effective tissue repair and resolution of ARDS, while others develop irreversible pulmonary fibrosis with high mortality $[12,13]$. The balance between injury and repair is a key point in the recovery of respiratory function in ARDS. ARDS is a main reason for severe and critical COVID-19, which is critical to global human health currently. The treatment experience from COVID-19 showed that early repair and early 
injury are accompanied in severe ARDS. This study is also concerned about this character of ARDS. Choosing HELF to explore TGF- $\beta /$ Smad signaling is from the perspective of early repair accompanied by injury. It could provide evidence for over-repair and treatment in the early stages of ARDS in vitro.

TGF- $\beta 1$ is a multifunctional cytokine that plays an important role in progressive pulmonary fibrosis. However, the role of TGF- $\beta 1$ is unclear in lung inflammation and fibrosis. In patients with septic shock, persistent ARDS is accompanied by increased circulating TGF- $\beta 1$ levels [14]. Furthermore, ARDS patients with fatal outcomes exhibit higher TGF- $\beta 1$ concentrations than survivors [14]. These results suggest that sepsis-induced ARDS with a fatal outcome is associated with increased serum TGF- $\beta 1$ levels [14]. Producing and maintaining a sufficient amount of TGF- $\beta$ can cause tissue fibrosis in multiple organs, wherein damaged epithelial cells can produce and activate TGF- $\beta$, which drives the expansion and activation of fibroblasts. In addition, since alveolar epithelial cells and fibroblast interactions can affect collagen deposition, TGF- $\beta$ and fibroblasts play important roles in pulmonary fibrosis $[15,16]$. Given this, we used TGF- $\beta 1$ to stimulate lung fibroblasts and observed its effects on pulmonary fibrosis and inflammation. $\alpha$-smooth muscle actin ( $\alpha$-SMA) was utilized as a marker of fibroblast activation. We demonstrated that $\alpha$-SMA expression and collagen synthesis were reduced and the cell cycle was markedly suppressed after downregulation of T $\beta R I$ expression. We found the expression of $\mathrm{p}$-Smad3 down-regulated after inhibiting the expression of the human T $\beta$ RI gene in HELF (Fig. 1d). Smad3 had been proved to play important role in fibrogenic response autocrine mechanism in vivo and in vitro [17-19]. These findings are consistent with the interruption of the TGF- $\beta$ signaling pathway by siRNA directed against T $\beta R I$.

This study showed that TGF- $\beta 1$ could not promote HELF cell proliferation, and it had no effect on the cell cycle. T $\beta$ RI siRNA, however, could inhibit the number of cells in the $S$ phase as well as cell proliferation. The reasons for these findings are complex, since the biological effects of lung fibroblasts may involve many factors, including the cell source, cell state, extracellular matrix composition, TGF$\beta 1$ concentration, interplay of receptors, ligands, and the existence of other relevant cytokine interactions $[15,16,20,21]$. Thus, additional research is required to explain these phenomena. TNF- $\alpha$ is a multipotent cytokine, which plays an important role in the pathogenesis of inflammatory cell ag- gregation, stimulation of inflammatory mediators, oxidative and nitrite stress, airway hyperresponsiveness, and tissue remodeling [22]. Elevated levels of TNF- $\alpha$ have been associated with various pulmonary inflammatory diseases, including asthma, chronic obstructive pulmonary disease (COPD), acute lung injury (ALI), ARDS, and pulmonary interstitial fibrosis (IPF) $[22,23]$. In our study, TNF- $\alpha$ was used as an indicator of the level of inflammation. RNAi targeting the T $\beta R I$ gene was found to inhibit the TNF- $\alpha$ expression of HELF stimulated by TGF- $\beta 1$ and to induce inflammation.

In summary, we found that siRNAs mediated by a lentivirus could effectively inhibit the expression of the human T $\beta R I$ gene in HELF. Confidence in the dataset stems from the fact that the gene silencing originated from siRNAs designed from different regions of the T $\beta R I$ gene. After the downregulation of $T \beta R I$ expression, cell proliferation and the cell cycle were inhibited. RNAi targeting the T $\beta$ RI gene can inhibit the activation of HELF stimulated by TGF- $\beta 1$, and effectively suppress its effect on collagen synthesis (collagen I, collagen III), $\alpha$-SMA, and TNF- $\alpha$, IL-6 expression in HELF. The inhibition of T $\beta$ RI gene expression provides a theoretical basis for interfering with the TGF- $\beta 1 / T \beta R I$ signaling pathway and inhibiting pulmonary fibrosis and the inflammatory response. These results provide a basis for further in vivo studies.

Acknowledgements: The study was funded by the National Natural Science Foundation of China (No. 81760341, No. 81873928, No. 81801894), Basic science and cutting-edge technology research projects of Chongqing Science and Technology Commission (No. cstc2019jcyj-msxmX0301).

\section{REFERENCES}

1. Ware LB, Matthay MA (2000) The acute respiratory distress syndrome. $N$ Engl J Med 342, 1334-1349.

2. Bellani G, Laffey JG, Pham T, Fan E, Brochard L, Esteban A, Gattinoni L, van Haren F, et al (2016) Epidemiology, patterns of care, and mortality for patients with acute respiratory distress syndrome in intensive care units in 50 countries. JAMA 315, 788-800.

3. Fan E, Brodie D, Slutsky AS (2018) Acute respiratory distress syndrome: Advances in diagnosis and treatment. JAMA 319, 698-710.

4. Cabrera-Benítez NE, Parotto M, Post M, Han B, Spieth PM, Cheng WE, et al (2012) Mechanical stress induces lung fibrosis by epithelial-mesenchymal transition. Crit Care Med 40, 510-517. 
5. Gharaee-Kermani M, Hu B, Phan SH, Gyetko MR (2009) Recent advances in molecular targets and treatment of idiopathic pulmonary fibrosis: focus on TGFbeta signaling and the myofibroblast. Curr Med Chem 16, 1400-1417.

6. Keshari RS, Silasi-Mansat R, Zhu H, Popescu NI, Peer G, Chaaban H, Lambris JD, Polf H et al (2014) Acute lung injury and fibrosis in a baboon model of Escherichia coli sepsis. Am J Respir Cell Mol Biol 50, 439-450.

7. Wang YW, Liou NH, Cherng JH, Chang SJ, Ma KH, Fu E, Liu JC, Dai NT (2014) siRNA-targeting transforming growth factor- $\beta$ type I receptor reduces wound scarring and extracellular matrix deposition of scar tissue. J Invest Dermatol 134, 2016-2025.

8. Mazzocchi LC, Vohwinkel CU, Mayer K, Herold S, Morty RE, Seeger W, Vadász I (2017) TGF- $\beta$ inhibits alveolar protein transport by promoting shedding, regulated intramembrane proteolysis, and transcriptional downregulation of megalin. Am J Physiol Lung Cell Mol Physiol 313, 807-824.

9. van Meeteren LA, ten Dijke P (2012) Regulation of endothelial cell plasticity byTGF- $\beta$. Cell Tissue Res 347, 177-186.

10. Wilson RC, Doudna JA (2013) Molecular mechanisms of RNA interference. Annu Rev Biophys 42, 217-239.

11. Cabrera-Benitez NE, Laffey JG, Parotto M, Spieth PM, Villar J, Zhang H, Slutsky AS (2014) Mechanical ventilation-associated lung fibrosis in acute respiratory distress syndrome: a significant contributor to poor outcome. Anesthesiology 121, 189-198.

12. Hendrickson CM, Crestani B, Matthay MA (2015) Biology and pathology of fibroproliferation following the acute respiratory distress syndrome. Intensive Care Med 41, 147-150.

13. Silasi-Mansat R, Zhu H, Georgescu C, Popescu N, Keshari RS, Peer G, Lupu C, Taylor FB (2015) Complement inhibition decreases early fibrogenic events in the lung of septic baboons. J Cell Mol Med 19, 2549-2563.

14. de Pablo R, Monserrat J, Reyes E, Díaz D, RodríguezZapata M, la Hera Ad, Prieto A, Alvarez-Mon M
(2012) Sepsis-induced acute respiratory distress syndrome with fatal outcome is associated to increased serum transforming growth factor beta-1 levels. Eur J Intern Med 23, 358-362.

15. Sheppard D (2015) Epithelial-mesenchymal interactions in fibrosis and repair. Transforming growth factor- $\beta$ activation by epithelial cells and fibroblasts. Ann Am Thorac Soc 12, Suppl 1, 21-23.

16. Knudsen L, Ruppert C, Ochs M (2017) Tissue remodelling in pulmonary fibrosis. Cell Tissue Res 367 , 607-626.

17. Guan S, Liu Q, Han F, Gu W, Song L, Zhang Y, Guo X, $\mathrm{Xu}$ W (2017) Ginsenoside Rg1 ameliorates cigarette smoke-induced airway fibrosis by suppressing the TGF- $\beta 1 /$ Smad pathway in vivo and in vitro. Biomed Res Int 2017, ID 6510198.

18. Cutroneo KR (2006) Evidence for TGF-beta1 and bleomycin intracellular signaling through autocrine regulation of Smad 3 binding to the proximal promoter of the Smad 7 gene. J Cell Biochem 97, 933-939.

19. Martin MM, Buckenberger JA, Jiang J, Malana GE, Knoell DL, Feldman DS, Elton TS (2007) TGF-beta1 stimulates human AT1 receptor expression in lung fibroblasts by cross talk between the Smad, p38 MAPK, JNK, and PI3K signaling pathways. Am J Physiol Lung Cell Mol Physiol 293, 790-799.

20. Aykul S, Martinez-Hackert E (2016) Transforming growth factor- $\beta$ family ligands can function as antagonists by competing for type II receptor binding. $J$ Biol Chem 291, 10792-10804.

21. Blaauboer ME, Boeijen FR, Emson CL, Turner SM, Zandieh-Doulabi B, Hanemaaijer R, Smit TH, Stoop R (2014) Extracellular matrix proteins: a positive feedback loop in lung fibrosis? Matrix Biol 34, 170-178.

22. Malaviya R, Laskin JD, Laskin DL (2017) Anti-TNFa therapy in inflammatory lung diseases. Pharmacol Ther 180, 90-98.

23. Kalliolias GD, Ivashkiv LB (2016) TNF biology, pathogenic mechanisms and emerging therapeutic strategies. Nat Rev Rheumatol 12, 49-62. 